\title{
Improvement the Performance of Drum Boiler in Thermal Power Plant using Hybrid Model through the Adaptive Neuro-Fuzzy Controller
}

\author{
Khalid Faisal Sultan*, Hosham Salim Anead and Malak Moneeryounis \\ Electromechanical Engineering Department, University of Technology, Baghdad, Iraq; \\ ksultan61@yahoo.com, Hoshams.2000@yahoo.com, moneer.maroof@yahoo.com
}

\begin{abstract}
Objectives: This Study tackles how the process of Neuro-fuzzy control that allows observing and controlling the steam pressure and temperature than conventional PI at drum boiler in the power station. It is used to increase the thermal efficiency of the boiler while it has helped to maintain the Turbine not to reach wet vapor which is considered the best method, more accurate compared to the basic conventional method of PI. Methods/Statistical Analysis: The method of hybrid control was used by Neuro-fuzzy in model design simulation by the Matlab program, which led to data training and testing. It is compared with conventional method of PI (Rise Time (sec) - Settling Time (sec) - Overshoot (\%) Peak Peak Time (sec)) by tracking the temperature, steam pressure and to reach the degree of vapor in less time and accuracy. Findings: ANFIS tracks the path of parameters (Temperature - Pressure) more accurately and superior than the traditional method PID and this leads to enhanced, improved and more thermal efficient performance in a drum of the boiler. It shows that the ratio of the overshoot in the PI is 15.68 for the temperature while in the steam for pressure 13.22 bars either in Neuro-fuzzy is in both parameters zero. Thus, ANFIS seems to be more accurate in tracking and shorter time and the absence of the ratio Overshoot compared to the basic conventional method of PI. Application/Improvements: Strategy is presented in the promotion and development of control of drum steam boilers through the simulations model, which was constructed using the hybrid theory and compared to the main theory PI as shown in the results.
\end{abstract}

Keywords: Drum Boiler, Hybrid Model, Neuro-Fuzzy, Thermal Power Plant, PI

\section{Introduction}

The boilers are one of the most important instruments in thermo-electrical power station especially the main burning process happens on it. As all we known, in the boiler the steam water is heated and converts to superheat steam by burning any amount of fuel. There for it is necessary to protect this part and available safety operation conduction and that's was by controlling in some parameters of steam water that entering the boiler and the fuel ${ }^{1-2}$.

Figure 1 Show you the boiler in one of the thermoelectrical power station. A boiler is a closed vessel in which contain grid from pipes they're passing through its steam water from inters point and to end that convert to superheat steam to enter the turbine. Addition of these grids the boiler including many (in and out) let's pipe used for fuel. The steam generators are integral components of steam turbines which are used as prime movers to drive generators to produce electricity in all thermal. Adaptive neural-fuzzy inference system of artificial intelligence methods where application is described as neuro-fuzzy method to improve thermal efficiencybymonitoring temperature of dry flue gas and steam pressure. The most common losses are the discharge of the hot chimney gas into the atmosphere through the chimney. The aim of this article is used to increase the thermal efficiency of the

${ }^{*}$ Author for correspondence 
boiler by tracking the temperature, steam pressure And to reach the degree of vapor in less time and accuracy, which also helps to maintain the Turbine not to reach wet vapor by using Adaptive Neuro-fuzzy Inference System method. Which is considered the best method, more accurate in tracking and shorter time and the absence of the ratio Overshoot compared to the Basic conventional method of PI.

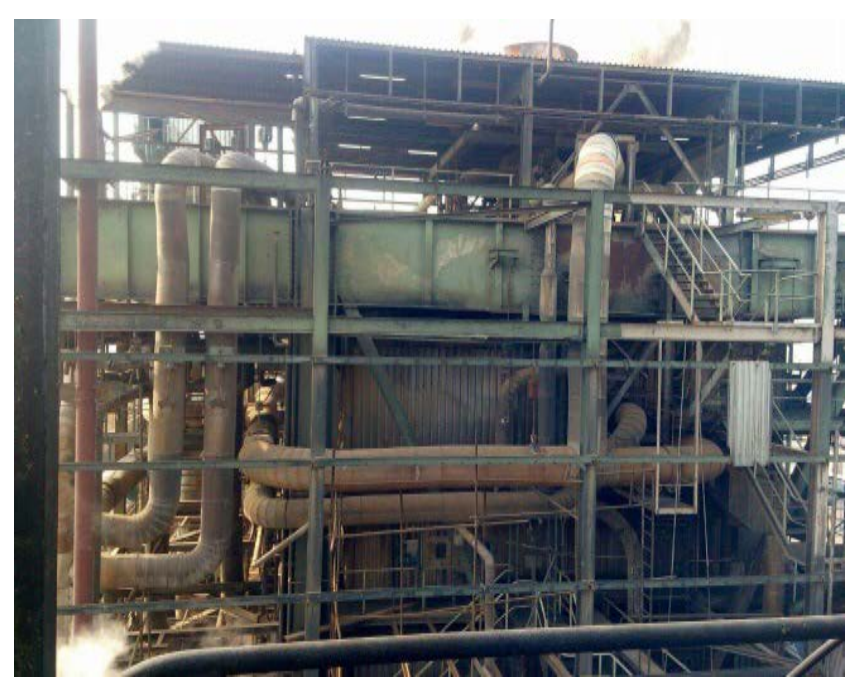

Figure 1. Steam boiler in power plant AL - Dura.

\section{Neuro-Fuzzy Model}

Neural-fuzzy model is involved with deciding the samples of the numeric data that are running system behavior. This type of modeling has two purposes: Primary, providing a model allows for monitoring and possibly predicts a way unknown system secondary producing a model for the best perception of the non-linear system. The model, in this case, is established on the rules; Fuzzy logic has been used to contain a set of rules represented "IF - THEN". The ability to learn from feeding forward networks support bleeding if model the architecture of the network, once properly, must to rules without losing information. Many have studied this idea accurately the authors began with the beginning of the $1990 \mathrm{~s}^{3-11}$, remains an important research area. Neuro-fuzzy is available in MATLAB ${ }^{12}$.

\section{ANFIS Architecture}

The architecture at ANFIS belongs to artificial intelligence networks, which are concerned with the best control, accuracy and durability of fuzzy and neural. This will explain the mechanics of the installation and work of the Neuro-fuzzy system for each layer of layers where each layer consists of two inputs $\mathrm{X}-\mathrm{Y}$ and one output $\mathrm{Z}$. Surgeon fuzzy model has represented in rules as Figure 2.

- rule1: IF $\mathrm{x}$ is $A_{1}$ and $\mathrm{y}$ is $B_{1}$,

- Then $\mathrm{f} 1=p_{1} \mathrm{x}+q_{2} \mathrm{y}+r_{1}$

- rule2: IF $\mathrm{x}$ is $A_{2}$ and $\mathrm{y}$ is $B_{2}$,

Then $F_{2}=p_{2} \mathrm{x}+q_{2} \mathrm{y}+r_{2}$

Each layer containing the node would be associated with the fuzzy-neural system with a particular step in the fuzzy inference process.

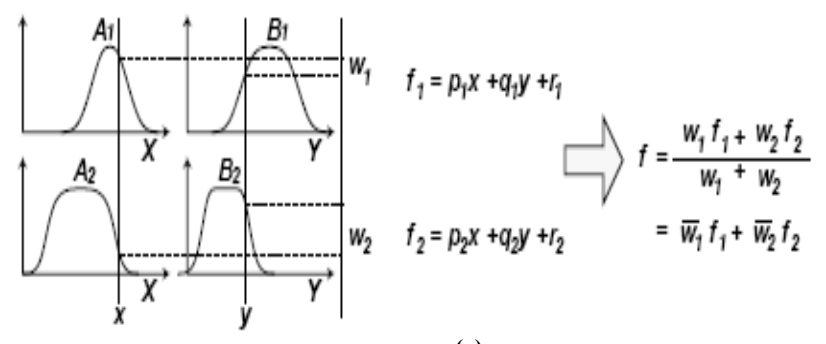

(a)

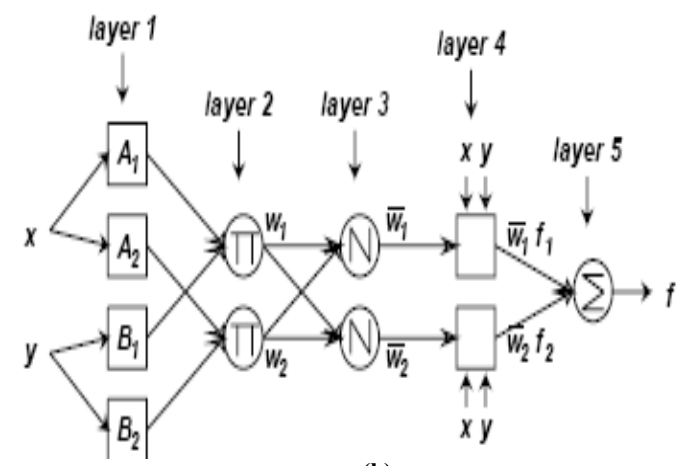

(b)

Figure 2. (a) Reasoning type of sugeno fuzzy, (b) Architecture of equivalent ANFIS.

Layer 1: Adaptive nodes include that produce a degree of membership value based on premise parameters, using a proper parameterized membership function, such as that the generalized bell function:

$$
\begin{aligned}
& O_{1, i}=\mu_{B_{i-2}}(x) i=3,4 \\
& \mu_{A}(\mathrm{x})=\frac{1}{1+\left[\left(x-c_{i}\right)^{2} / a_{i}^{2}\right]^{b_{i}}}
\end{aligned}
$$


Where: the degrees of membership functions are $\mu_{A i}$ and $\mu_{A B i-2}$ for the fuzzy sets $A_{i}$ and $B_{i}$, respectively and the parameters of a membership function are $\left\{a_{i}, b_{i}, c_{i}\right\}$ that lead to change the format of the membership function.

Layer 2: Includes in this layer, the node is called the circle node and is symbolized as $\pi$ and is fixed which is not adaptable. The output node is the result of multiplication of the signal coming into the node and delivered to the next node. In this layer, each node is represented by firing strength for each rule. Operator T-norm with general performance, such as the AND, is applied to get the output.

$$
O_{2, i}=w_{i}=\mu_{A i}(\mathrm{x}) \times \mu_{B i}(\mathrm{x}) \quad \mathrm{i}=1,2
$$

The output is represented by firing strength of each rule $\left(w_{i}\right)$.

Layer 3: This layer all nodes will be fixed and symbolized by $\mathrm{N}$. the output is normalized firing strengths. Where the ratio of firing strength to the sum of the firing strengths of all rules is called output node.

$$
O_{3, i}=\overline{w_{i}}=\frac{w_{i}}{w_{1}+w_{2}} \quad \mathrm{i}=1,2
$$

Layer 4: The adaptive nodes calculate the rule outputs based upon consequent parameters using the following function:

$$
O_{4, i}=\overline{w_{i}} f_{i}=\overline{w_{i}}\left(p_{i} \mathrm{x}+q_{i} \mathrm{y}+r_{i}\right)
$$

Where: $\bar{w}_{i}$ is the normalized firing strength from layer 3 , and $\left\{p_{i}, q_{i}, r_{i}\right\}$ is the consequent parameter set of the node.

Layer 5: The last layer will be Single node is a constant node O5,1(output), which computes all output as the aggregation of all incoming signals:

$$
o_{5,1}=\text { output }=\sum \overline{w_{i}} f_{i}
$$

When premise parameters are fixed:

$$
\mathrm{F}=\frac{w_{1}}{w_{1}+w_{2}} f_{1}+\frac{w_{2}}{w_{1}+w_{2}} f_{2}=\overline{w_{1}} f_{1}+\overline{w_{2}} f_{2}
$$

This parameters are linear in the consequent $\mathrm{p}\left(p_{1}, q_{1}\right.$ , $r_{1}, p_{2}, q_{2}$ and $\left.r_{2}\right)$.

\section{Water Tube Steam Boiler ANFIS Model}

Boiler water and steam unit 6 of AL - Dura power plant is a major structure from the thermoelectric power stations, origin Germany. In thermal sketch of the thermoelectric power plants, show in Figure 3.

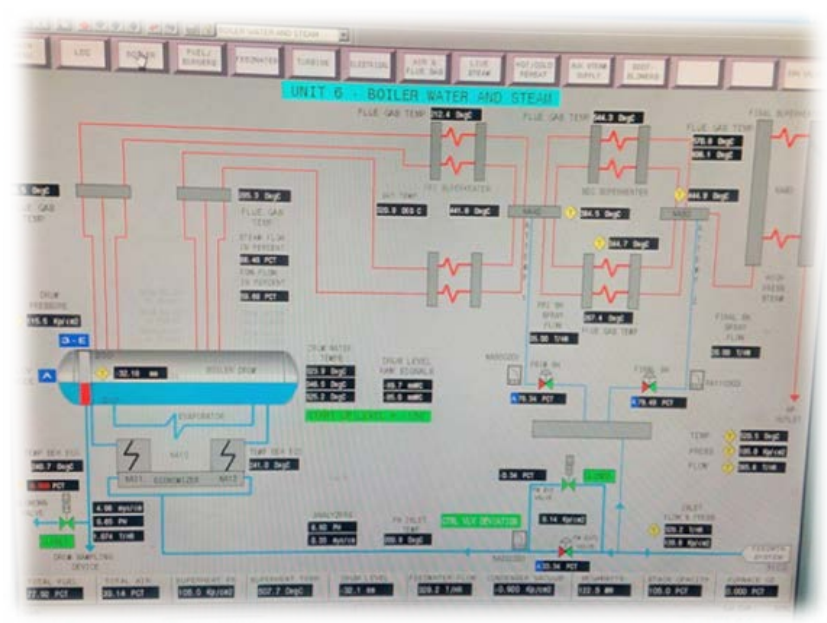

Figure 3. Thermal sketch of the thermoelectric power plant AL - Dura.

For the purpose of training and testing the installation of ANFIS model for Boiler steam following the behavior of the available parameters: pressure (bar), Temperature $\left({ }^{\circ} \mathrm{C}\right)$, water level $\left(\mathrm{m}^{3} / \mathrm{h}\right)$, gas flow $\left(\mathrm{m}^{3} / \mathrm{h}\right)$, air/ fuel, and flame. However, those parameters are available during system data monitoring. In Figure 4 are visible in the super heaters. The drum as component part of the steam boiler and the water circuit from the boiler input as far as the working steam which is collected on the steam main. As principal perturbation is that the water injection cooling system for the steam temperature management from the drum output as a way because the operating steam and that acts between the boiler steam heating stages.

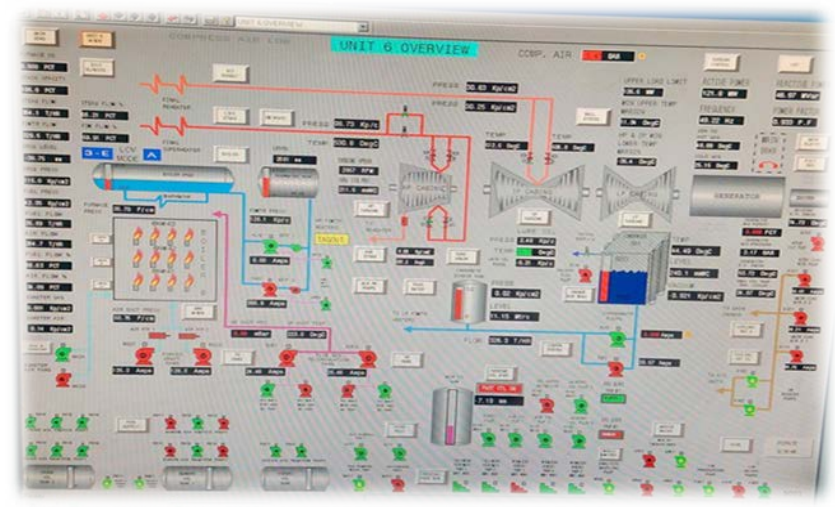

Figure 4. Monitoring data for power plant AL - Dura.

For the purpose of training and testing the installation of ANFIS uses the tools of fuzzy logic of the MATLAB, 
which includes these tools adaptive neurological learning techniques ${ }^{11}$. Here the behavior of steam boilers derived from model 201 data. The manual counting process was $70 \%$ training and $30 \%$ testing. The basis of the idea of Adaptive Neuro-fuzzy is very easy, to the intent of calculating the parameters (steam pressure and temperature) of the membership functions that allow for the superior system of fuzzy inference connected with tracking the input and output data given. In this Figure 5 simulation ANFIS steam boiler and in block of structural simulation of temperature ANFIS controller Figure 6.

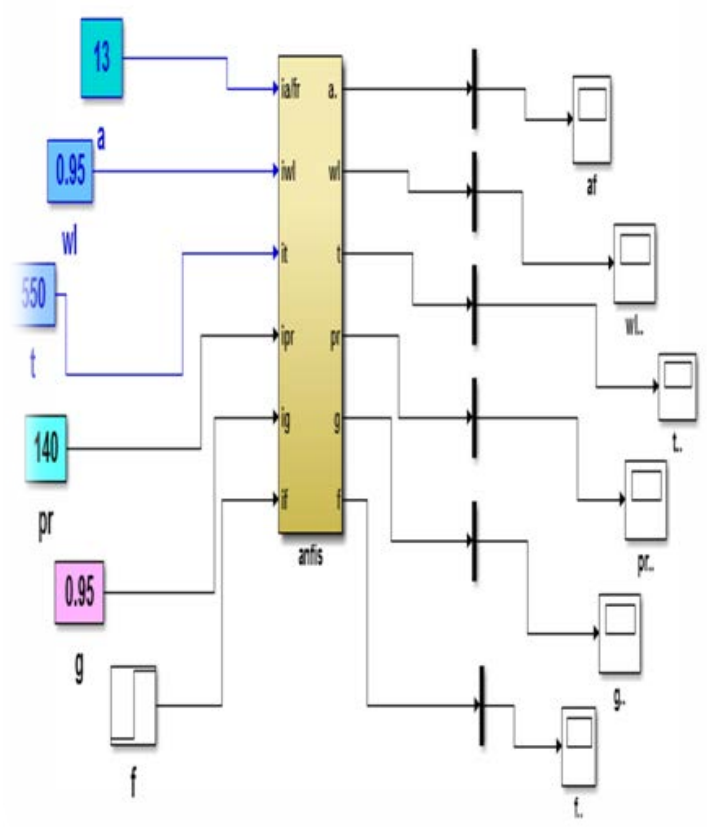

Figure 5. Simulation ANFIS steam boiler.

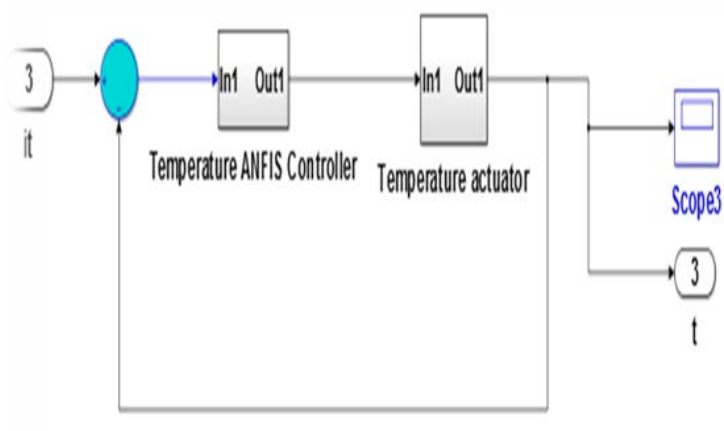

Figure 6. Block of structure simulation of temperature ANFIS controller.

When training data exists types of membership function (triangular, trapezoidal, bell shaped, Gaussian) a lower error rate would be the best type. Temperature operating point is max and min respectively (520-550) ${ }^{0} \mathrm{C}$ is the best type $\mathrm{mf}$ Gaussian, average error $=0.0098757$ while steam pressure of operation point is max and min respectively (130-140) bar is the best type $\mathrm{mf}$ Triangular, average error $=0.000242$

\section{Simulation Analysis and Discussion}

The steam vapor generated by the temperature and pressure steam where used in this paper to control it and entered in turbine stages by using the Neuro-fuzzy Inference system simulation model of the Matlab (2014a) program and obtained the following results as showed

Table 1. Training error of temperature

\begin{tabular}{|l|l|l|l|l|}
\hline Type $\mathbf{m f}$ & N. layer & N. Iteration & Average Error & Error \\
\hline & & & Constant & \\
\hline Triangular & 6 & 50 & 0.093401 & \\
\hline Trapezoidal & 6 & 50 & 1.82522 & \\
\hline Bell shapped & $\mathbf{6}$ & 50 & 0.0484182 & \\
\hline symmetric Gaussian function & 6 & 50 & 0.243195 & \\
\hline & & & Linear & \\
\hline Triangular & 6 & 50 & 0.099521 & \\
\hline Trapezoidal & 6 & 50 & 0.122364 & \\
\hline Bell shapped & $\mathbf{6}$ & 50 & 0.0376103 & \\
\hline symmetric Gaussian function & 6 & 50 & 0.00987576 & Best \\
\hline
\end{tabular}


in the Figures 7-9. Training Error of Temperature and Pressure steam as indicated in Tables 1-2.

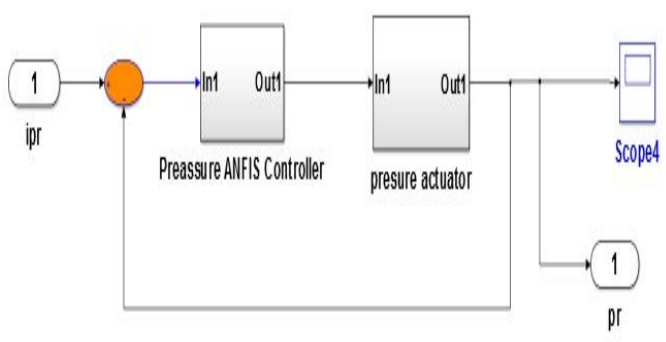

Figure 7. Block of structure simulation of pressure ANFIS controller.
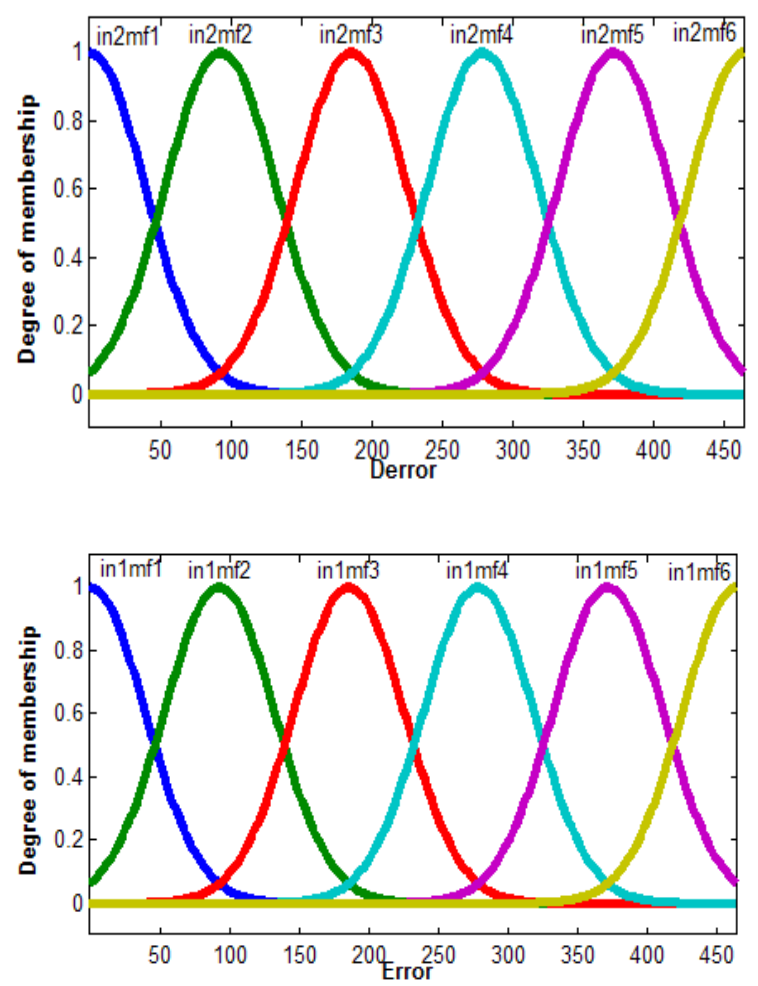

Figure 8. Temperature of membership function plot.

Now, the showing of the proposed controller has discussed the point of temperature in the drum boiler that temperature regulation by neuro-fuzzy controller is verified for point of step input of $550^{\circ} \mathrm{C}$. The performance graphs are presented in Figure 10. The adaptive neurofuzzy inference system tracked temperature precisely and during the less period of time. This representation the delicate performance of the proposed controller in tracking the temperature thus good regulation, compared with PI controller while it shows that the performance of the PI controller is having large overshoot and more time than ANFIS controller for the first peak, as shown in Table 3.

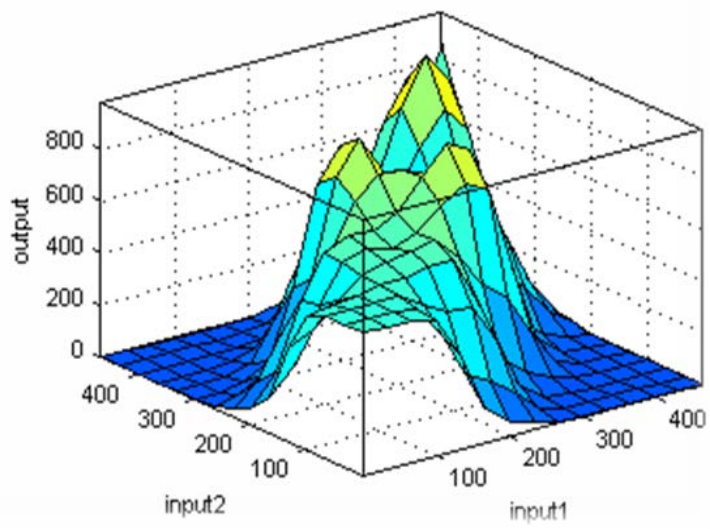

Figure 9. ANFIS surface of temperature.

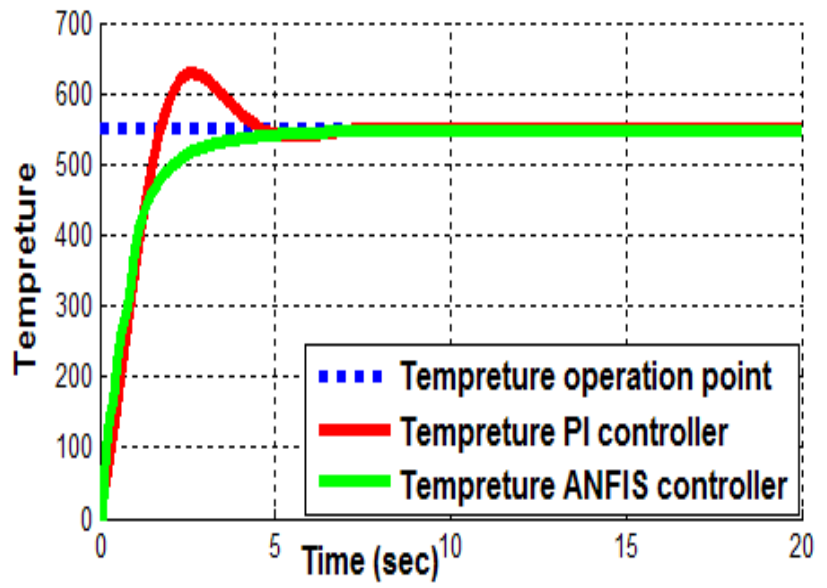

Figure 10. State response curves under dry flue gas temperature.

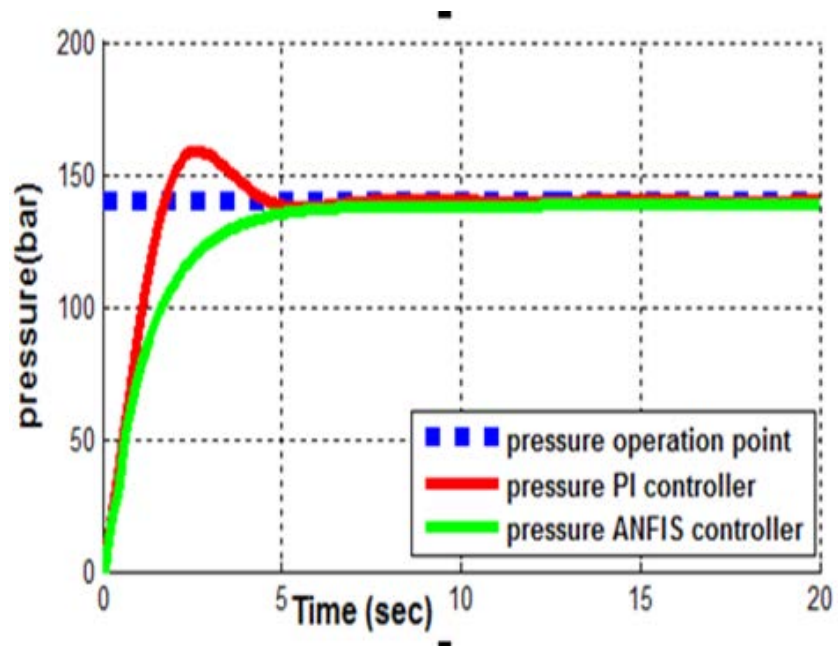

Figure 11. State response curves pressure. 
Table 2. Training error of pressure steam

\begin{tabular}{|l|l|l|l|l|}
\hline Type mf & N. layer & N. Iteration & Average Error & Error \\
\hline & & & Constant & \\
\hline Triangular & 6 & 50 & 0.0057646 & \\
\hline Trapezoidal & 6 & 50 & 0.380415 & \\
\hline Bell shapped & $\mathbf{6}$ & 50 & 0.0231001 & \\
\hline symmetric Gaussian function & 6 & 50 & 0.0231521 & \\
\hline & & & Linear & Best \\
\hline Triangular & 6 & 50 & 0.000242203 & \\
\hline Trapezoidal & 6 & 50 & 0.000906069 & \\
\hline Bell shapped & $\mathbf{6}$ & 50 & 0.00236316 & \\
\hline symmetric Gaussian function & 6 & 50 & 0.0011645 & \\
\hline
\end{tabular}

Table 3. Comparison parameters between ANFIS and PI for temperature of steam boiler

\begin{tabular}{|l|l|l|l|l|l|}
\hline Parameter & $\begin{array}{l}\text { Rise Time } \\
(\mathrm{sec})\end{array}$ & $\begin{array}{l}\text { Settling Time } \\
(\mathrm{sec})\end{array}$ & Overshoot & Peak & $\begin{array}{l}\text { Peak Time } \\
(\mathrm{sec})\end{array}$ \\
\hline $\begin{array}{l}\text { temperature } \\
\text { ANFIS }\end{array}$ & 1.8137 & 4.2284 & 0 & 548.4 & 20 \\
PI & 1.267 & 6.091 & 15.68 & 636.24 & 2.7 \\
\hline
\end{tabular}

Table 4. Comparison parameters between ANFIS and PI for pressure steam

\begin{tabular}{|l|l|l|l|l|l|}
\hline Parameter & $\begin{array}{l}\text { Rise Time } \\
(\mathrm{sec})\end{array}$ & $\begin{array}{l}\text { Settling Time } \\
(\mathrm{sec})\end{array}$ & $\begin{array}{l}\text { Overshoot } \\
\%\end{array}$ & Peak & $\begin{array}{l}\text { Peak Time } \\
(\mathrm{sec})\end{array}$ \\
\hline $\begin{array}{l}\text { pressure } \\
\text { ANFIS }\end{array}$ & 2.8087 & 5.1472 & 0 & 138.19 & 20 \\
PI & 1.292 & 4.3477 & 13.22 & 158.52 & 2.7 \\
\hline
\end{tabular}

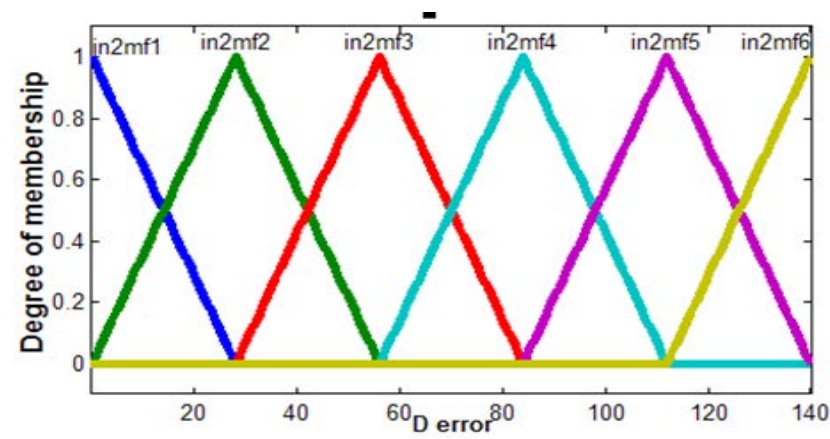

Also, the performance of the proposed controller has debated the point of pressure steam in the boiler drum. The regulation trajectory of pressure steam by using neuro-fuzzy controller to prove for point of step input for the size of 140 bars. The performance schemes are shown in Figures 11-13.

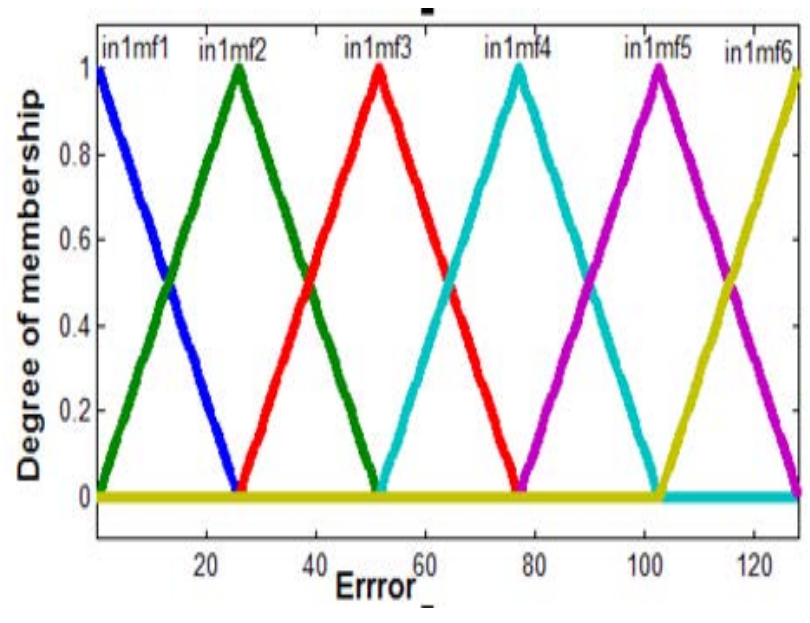

Figure 12. Pressure membership function plot.

The neuro-fuzzy controller tracked steam pressure precisely and within the minimal period of time. This 
shows the accurate performance of the proposed controller in tracking the pressure thus good regulation, and also to make compared with PI controller to prove better controller in intelligent Artificial and it shows that the performance of the PI controller is having large overshoot and more time than ANFIS controller for the first peak, as shown in Table 4.

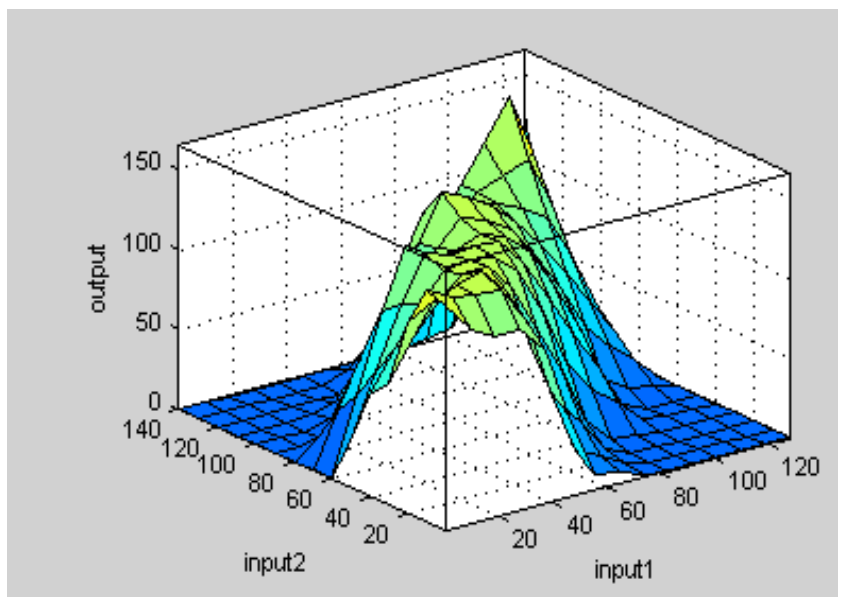

Figure 13. ANFIS surface of pressure.

\section{Conclusion}

The temperature parameter for steam boiler was regulated at the thermal station by ANFIS control. 201 data were used, and the best Gaussian function was used after training as shown in Training Error of Temperature, when it was a membership function: 6 , and Number of epochs: 50, ANFIS was obtained better and more accurate in tracking and controlling the temperature path than the PI conventional, and it is shown in Comparison parameters between ANFIS and PI for temperature of steam Boiler where the ratio of the overshoot is 0 and the rise time is greater For its speed and peak time is smaller than PI. Also pressure steam was regulated by Neuro-Fuzzy controller when data were used 201, triangular function, as presented in Training Error of Pressure steam while Comparison parameters between ANFIS and PI for pressure steam. It shows the accuracy and durability of ANFIS from the traditional method from through best overshoot. Peak time is best and the least time period.

\section{Reference}

1. Lucian M, Iosif O, Catalin D, DorinI. Neuro-fuzzy models of thermoelectric power station installations. International Conference on Computational Intelligence for Modeling, Control and Automation and International Conference on Intelligent Agents, Web Technologies and Internet Commerce; 2005. p. 899-904.

2. Nurnberger A, Nauck D, Kruse R, Merz L. A Neuro-fuzzy development tool for fuzzy controllers under MATLAB/ SIMULINK. Proceedings 5th European Congress on Intelligent Techniques and Soft Computing; 1997.

3. Kumar R, Kaushik S, Kumar A. Energy and exergy analysis of non-reheat thermal power plant. Proceedings of International Conference on Energy and Environment; 2009. p. 608-11.

4. Horikawa S, Furuhashi T, Uchikawa Y. A new type of fuzzy neural network for linguistic fuzzy modeling. Proceedings $2^{\text {nd }}$ International Conference on Fuzzy Logic and Neural Networks; 1992. p. 1053-6.

5. Culliere T, Corrieu J. Neuro-fuzzy modeling of nonlinear systems for control purposes. Proceedings IEEE International Conference on Fuzzy Systems; 1995. p. 200916. Crossref

6. Jang SRJ. ANFIS: Adaptive network based fuzzy inference system. IEEE Trans on Systems, Man and Cybernetics. 1993; 23(3):665-85. Crossref

7. Jang J. Neuro-fuzzy modeling: Architecture, Analyses and Applications. Berkeley, USA: University of California; 1992. p. 1-310.

8. Jang J, Sun C. Neuro-fuzzy modelling and control. Proceedings IEEE. 1995; 83(3):378-406. Crossref

9. Jang J, Sun C, Mizutani E. Neuro-Fuzzy and Soft Computing - A Computational Approach to Learning and Machine Intelligence. New Jersey: Prentice Hall; 1997. p. 1-640.

10. Ying B, Dali W. Advanced of fuzzy logic technologies in industrial application. Springer; 2006.

11. Rabah AC. Improved Controller for a thermal power plant [Thesis]. Institute de Genie Electrique; 2012.

12. Math Works. Fuzzy Logic Toolbox User's Guide. The Math Works, Technical Report. 2014. 